\title{
The Experiment for Direct Dark Matter Searches with Liquid Ar Detector
}

\author{
B.M. Ovchinnikov ${ }^{1, *}$, Yu.B. Ovchinnikov ${ }^{2}$, V.V. Parusov ${ }^{1}$ \\ ${ }^{1}$ Institute for Nuclear Research of Russian Academy of Sciences, Moscow, Russia \\ ${ }^{2}$ National Physical Laboratory, Teddington, Middlesex, TW11 0LW, UK \\ *Corresponding Author: ovchin@inr.ru
}

Copyright $@ 2013$ Horizon Research Publishing All rights reserved.

\begin{abstract}
A novel experiment for direct searches of Dark Matter with a liquid argon double-phase chamber with a mass of liquid Ar up to $10^{4}$ tons is proposed. To suppress the $\beta-, \gamma-$ and $n_{0^{-}}$backgrounds, the comparison of scintillation and ionization signals for every event is suggested. The addition to liquid $\mathrm{Ar}$ of photosensitive $\mathrm{Ge}\left(\mathrm{CH}_{3}\right)_{4}(0.15 \mathrm{ppm})$ and the suppression of the triplet component of the scintillation signals by the addition of $100 \mathrm{ppm}$ of $\mathrm{Xe}$ ensures the detection of scintillation signals with $50 \%$ efficiency and provides a complete suppression of the electron background. Highly stable and reliable GEM detectors with pin-anodes are developed for the detection of photoelectrons and the bump of ionization electrons.
\end{abstract}

Keywords WIMPs Search with two-phase Ar-chamber with 50\% Efficiency Scintillation Detecting

\section{Introduction}

The experiment for direct searches of Weakly Interacting Massive Particles (WIMPs) with a 100litre Xe (Ar) double-phase chamber with the addition of photosensitive trimethylamine (TMA) [1] was proposed in [2]. As a result of absorption of the scintillation light, emitted by the atoms and molecules of $\mathrm{Xe}$, excited in a process of interaction of the recoil atoms and the background electrons, the ionization core is surrounded by photoelectron's cloud, the diameter of which is determined by the concentration of the TMA. The detection of the ionization core and photoelectrons, which is performed with high spatial resolution and efficiency, makes it possible to compare the ionization and scintillation signals and to highly suppress the background events.

The use of TMA as a photosensitive addition to the chamber with a large mass of liquid $\mathrm{Ar}$ is not possible because of the slight electro negativity of the TMA molecules [1, 3-7]. Due to this fact, the drift length of electrons in liquid $\mathrm{Xe}+4 \mathrm{ppmTMA}$, at a field of $3 \mathrm{kV} \cdot \mathrm{cm}^{-1}$, is as small as $100 \mathrm{~cm}[1]$.
The first results on Dark Matter searches with a 2.3-litre liquid Ar chamber have been received in [8], where the scintillation signals are detected by photomultipliers (PMT) with an efficiency of a few percent. All inner surfaces of the chamber are covered with tetra-phenyl-butadiene wave-shifter, which is used for conversion of the VUV light into visible emission. Electrons from the ionization core are transported by an electric field from the liquid Ar to the gas phase, where they produce an electroluminescent light, which is detected by PMT.

The one ton liquid Ar chamber was constructed in [9], where GEM detectors, made of metalized kapton, are used for the detection of electrons from the ionization core. However, using plastic GEM detectors in long-term experiments is rather problematic due to their low reliability[10-13].

In this work it is proposed to use $\mathrm{Ge}\left(\mathrm{CH}_{3}\right)_{4}$ (TMG) [14] $(0.15 \mathrm{ppm})$ as a photosensitive addition to the liquid $\mathrm{Ar}$ of the detector. Since TMG is a non-electronegative molecule, the electron drift length in the Ar +TMG mixtures may be equal to 20 meters, because these mixtures can be purified from electronegative impurities down to the level of $10^{-12}$ rel. vol. parts $\mathrm{O}_{2}$ [14-18].

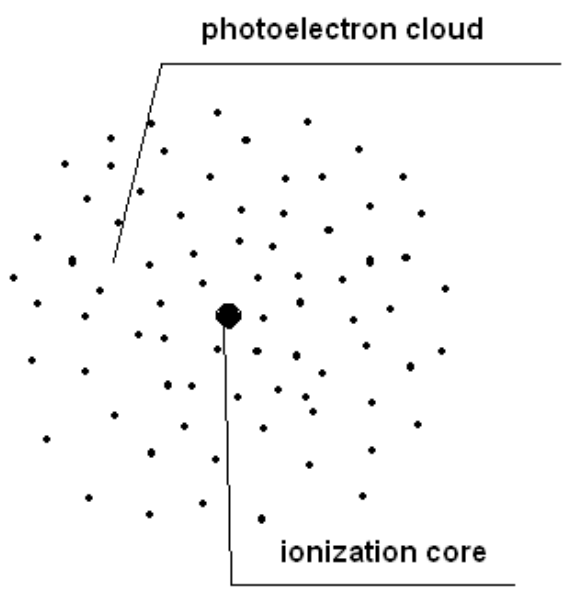

Figure 1. The event structure. 
In liquid Ar the energy of photons $\mathrm{Ar}_{2}{ }^{*} \rightarrow 2 \mathrm{Ar}+\mathrm{h} v$ is equal to $\sim(7.5-11.5) \mathrm{eV}$, while the ionization potential of TMG in liquid $\mathrm{Ar}$ is about $8.55 \mathrm{eV}$. As a result of this, the photons emitted by $\mathrm{Ar}_{2}{ }^{*}$ can ionize the TMG molecules, producing a cloud of photoelectrons around the ionization core [14] (Fig.1).

The recoil ions and the secondary and background electrons ionize the Ar atoms by producing electron - hole pairs and excited atoms (excitons), which leads in both cases to self - trapped exciton luminescence, which consists of a fast singlet ${ }^{1} \Sigma_{\mathrm{u}}{ }^{+}$component with $\tau_{I}=7 \pm 1 \mathrm{~ns}$ and a slow triplet ${ }^{3} \Sigma_{\mathrm{u}}^{+}$component with $\tau_{2}=1.6 \pm 0.1 \mu s[8]$.

The ratios between the singlet and the triplet intensities in liquid $\operatorname{Ar}[8]$ are equal to

$$
\mathrm{I}_{\mathrm{s}} / \mathrm{I}_{\mathrm{t}}=0.3\left(\mathrm{e}^{-}\right), 1.3(\alpha) \text { and } 3(\mathrm{nr})[8] \text {. }
$$

In some works (see Table 1), for suppression of the electron background the criterion $\mathrm{F}$ is used:

$$
\mathrm{F}=\mathrm{I}_{\mathrm{s}} /\left(\mathrm{I}_{\mathrm{s}}+\mathrm{I}_{\mathrm{t}}\right) \text {. }
$$

An alternative method for electron background suppression is to compare the ionization signal $\mathrm{S}_{2}$ and the scintillation signal $S_{1}$ for every event. The ratio between the ionization and scintillation signals in liquid $\mathrm{Ar}$ for $\mathrm{E}=100 \mathrm{keV}$, at an electric field intensity of $1 \mathrm{kV} / \mathrm{cm}$, is equal to:

$$
\mathrm{S}_{2} / \mathrm{S}_{1}=150\left(\mathrm{e}^{-}\right), 3(\alpha) \text { and } 10(\mathrm{nr})[8] .
$$

The additional charge in liquid $\mathrm{Ar}+0.15 \mathrm{ppm}$ TMG is produced mainly by photons, because the probability of ionization in the $\mathrm{Ar}_{2}{ }^{*}+\mathrm{TMG}$-collisions at this concentration of TMG is small [7].

The quantum efficiency of photo-ionization $\mathrm{h} v(128$ $\mathrm{nm})+\mathrm{TMG} \rightarrow \mathrm{TMG}^{+}+\mathrm{e}^{-}$in liquid Ar is equal to $50 \%$ [19].

The ionization core of a recoil ion or a background electron is surrounded by a photoelectron cloud of $\sim 10 \mathrm{~cm}$ in

\begin{tabular}{|c|c|c|c|c|c|c|}
\hline The name of project & $\begin{array}{l}\text { The target of } \\
\text { detector }\end{array}$ & $\begin{array}{l}\text { The detection } \\
\text { method }\end{array}$ & $\begin{array}{c}\text { The threshold of } \\
\text { detection }\end{array}$ & $\begin{array}{l}\text { The method } \\
\text { for } \\
\text { background } \\
\text { suppression }\end{array}$ & $\begin{array}{l}\mathrm{Ar}^{39} \text { concentration in } \\
\mathrm{Ar} \text {, } \\
\text { or other background }\end{array}$ & $\begin{array}{l}\text { The expected } \\
\text { result }\end{array}$ \\
\hline $\begin{array}{c}\text { "ArDM" A.Rubbia } \\
{[9]}\end{array}$ & $\begin{array}{c}\mathrm{Ar} \\
1000(850) \mathrm{kg} \\
\text { double-phase }\end{array}$ & $\begin{array}{c}\mathrm{S}_{2} / \mathrm{S}_{1}+\mathrm{F} \\
\mathrm{PMT}+\mathrm{GEM}\end{array}$ & $\mathrm{E}_{\mathrm{nr}}^{\min }=30$ кэВ & $\mathrm{S}_{2} / \mathrm{S}_{1}+\mathrm{F}$ & $10^{2}$ decays/t.s & $\begin{array}{l}\sigma(\text { WIMP }) \\
=10^{-45} \mathrm{~cm}^{2}\end{array}$ \\
\hline $\begin{array}{c}\text { "MiniClean" } \\
\text { Los Alamos [20] }\end{array}$ & $\begin{array}{c}\text { Ar liquid } \\
500(150) \mathrm{kg} \\
\text { single-phase } \\
\end{array}$ & $\begin{array}{c}\text { F } \\
92 \text { PMT }\end{array}$ & $\begin{array}{c}\mathrm{E}_{\mathrm{nr}}^{\min }=30 \\
\text { кэBM }^{\text {min }}(\mathrm{WIMP}) \\
=20 \mathrm{GeV}\end{array}$ & $\mathrm{F}$ & $10^{3}$ decay $/ t \cdot s$ & $10^{-45} \mathrm{~cm}^{2}$ \\
\hline $\begin{array}{c}\text { "Deap-3600" } \\
\text { Los Alamos [20] }\end{array}$ & $\begin{array}{c}\text { Ar liquid } \\
3600(1000) \mathrm{kg} \\
\text { single-phase }\end{array}$ & $\begin{array}{c}\mathrm{F} \\
266 \text { PMT }\end{array}$ & & $\mathrm{F}$ & $10^{3}$ decays $/ \mathrm{t} \cdot \mathrm{s}$ & $10^{-46} \mathrm{~cm}^{2}$ \\
\hline $\begin{array}{c}\text { "Clean" } \\
\text { Los Alamos [20] }\end{array}$ & $\begin{array}{c}\text { Ar liquid } \\
\text { 40(10)tons } \\
\text { single-phase } \\
\end{array}$ & $\begin{array}{c}\text { F } \\
\text { PMT }\end{array}$ & $\begin{array}{c}\mathrm{M}^{\mathrm{min}}(\mathrm{WIMP}) \\
=60 \mathrm{GeV}\end{array}$ & $\mathrm{F}$ & $<10^{2}$ decays $/ \mathrm{t} \cdot \mathrm{s}$ & $6 \cdot 10^{-47} \mathrm{~cm}^{2}$ \\
\hline \multirow[b]{2}{*}{$\begin{array}{l}\text { "Darvin" } \\
\text { [21] }\end{array}$} & $\begin{array}{c}\text { Ar } \\
\text { 20(10)tons } \\
\text { double-phase }\end{array}$ & $\begin{array}{c}\mathrm{S}_{2} / \mathrm{S}_{1}+\mathrm{F} \\
\text { avalanche } \\
\text { photodiodes } \\
+\mathrm{GEM}\end{array}$ & $\mathrm{E}_{\mathrm{nr}}^{\min }=30$ кэВ & $\begin{array}{c}\mathrm{S}_{2} / \mathrm{S}_{1}+\mathrm{F} \\
\text { Ksuppressio } \\
\mathrm{n}=10^{8}\end{array}$ & $<40 \mathrm{mBq} / \mathrm{kg}$ & $4 \cdot 10^{-48} \mathrm{~cm}^{2}$ \\
\hline & $\begin{array}{c}\mathrm{Xe} \\
8(5) \text { tons } \\
\text { double-phase }\end{array}$ & $\begin{array}{c}\mathrm{F}+\mathrm{S}_{2} / \mathrm{S}_{1} \\
\text { avalanche } \\
\text { photodiodes } \\
+\mathrm{GEM} \\
\end{array}$ & $\mathrm{E}_{\mathrm{nr}}^{\min }=10$ кэB & $\mathrm{F}+\mathrm{S}_{2} / \mathrm{S}_{1}$ & $\begin{array}{c}\text { Background } \\
10^{-4} \text { decays } / \mathrm{kg} \cdot \text { day } \cdot \mathrm{keV}\end{array}$ & \\
\hline \multirow{2}{*}{$\begin{array}{l}\text { Los Angeles } \\
\text { Dr.D.Cline [22]. } \\
\quad \text { (proposal) }\end{array}$} & $\begin{array}{c}\mathrm{Ar} \\
\text { 580(500)tons } \\
\text { double-phase }\end{array}$ & $\begin{array}{c}\mathrm{S}_{2} / \mathrm{S}_{1} \\
12000 \text { avalanche } \\
\text { Photodiodes }\end{array}$ & $\begin{array}{l}\mathrm{M}^{\mathrm{min}}(\mathrm{WIMP}) \\
\quad \cong 20 \mathrm{GeV}\end{array}$ & $\mathrm{S}_{2} / \mathrm{S}_{1}+\mathrm{F}$ & $<10$ decays $/ \mathrm{t} \cdot \mathrm{s}$ & $10^{-48} \mathrm{~cm}^{2}$ \\
\hline & $\begin{array}{c}\mathrm{Xe} \\
\text { 146(100)tons } \\
\text { double-phase } \\
\end{array}$ & $\begin{array}{c}\mathrm{S}_{2} / \mathrm{S}_{1}+\mathrm{F} \\
3740 \text { avalanche } \\
\text { Photodiodes } \\
\end{array}$ & $\begin{array}{l}\mathrm{M}^{\mathrm{min}}(\mathrm{WIMP}) \\
\cong 6 \mathrm{GeV}\end{array}$ & $\begin{array}{l}\mathrm{S}_{2} / \mathrm{S}_{1}+\mathrm{F} \\
\mathrm{K}=10^{3}\end{array}$ & & \\
\hline $\begin{array}{c}\text { INR of RAS } \\
\text { (proposal) Dr. } \\
\text { B.M.Ovchinnikov } \\
\text { [23] }\end{array}$ & $\begin{array}{c}\mathrm{Ar}+\mathrm{Ge}\left(\mathrm{CH}_{3}\right)_{4} \\
(0,15 \mathrm{ppm}) \text { or } \\
\mathrm{Ar}+\mathrm{C}_{2} \mathrm{H}_{4}(2 \\
\mathrm{ppm}) \\
10000 \text { tons } \\
\text { double-phase }\end{array}$ & $\begin{array}{l}\mathrm{S}_{2} / \mathrm{S}_{1} \\
\mathrm{GEM}\end{array}$ & $\mathrm{E}_{\mathrm{nr}}^{\min }=10$ кэВ & $\begin{array}{c}\mathrm{S}_{2} / \mathrm{S}_{1} \\
\mathrm{~K}>10^{10}\end{array}$ & $10^{3}$ decays $/ \mathrm{t} \cdot \mathrm{s}$ & $\leq 10^{-48} \mathrm{~cm}^{2}$ \\
\hline
\end{tabular}
diameter [14], at a concentration of TMG of $0.15 \mathrm{ppm}$.

Table 1. The detectors for direct DM searches 
The measurement of the number of photoelectrons surrounding the ionization core ensures the high efficiency measurement of the scintillation signal amplitude, the efficiency of which must be better than in the case of using photomultipliers, and this should make it possible to obtain high suppression of the background.

The dependence $\mathrm{S}_{2} / \mathrm{S}_{1}=\mathrm{f}\left(\mathrm{E}_{\mathrm{nr}}\right)$ is shown in Fig.5 of work [8]. The quantity $\mathrm{S}_{2} / \mathrm{S}_{1}$, obtained by extrapolation, is equal to 40 for $E_{n r}=10 \mathrm{keV}$. The number of photons for $E_{n r}=30 \mathrm{keV}$ is equal to300 [8]. The ratio $S_{2} / S_{1}$ for electron background is changed by little within the working range.

At present, several experimental installations with high mass of liquid Ar for the search of Dark Matter have been proposed and developed, the main parameters of which are given in Table 1.

\section{Experimental Setup}

As an example, the design for a chamber with a mass of liquid $\mathrm{Ar}$ of 20 tons is shown in Fig.2. The ionization electrons and photoelectrons are detected with GEM and pin-anodes of high reliability and stability [10-13]. The diameter of GEM is equal to $\sim 70 \mathrm{~cm}$.

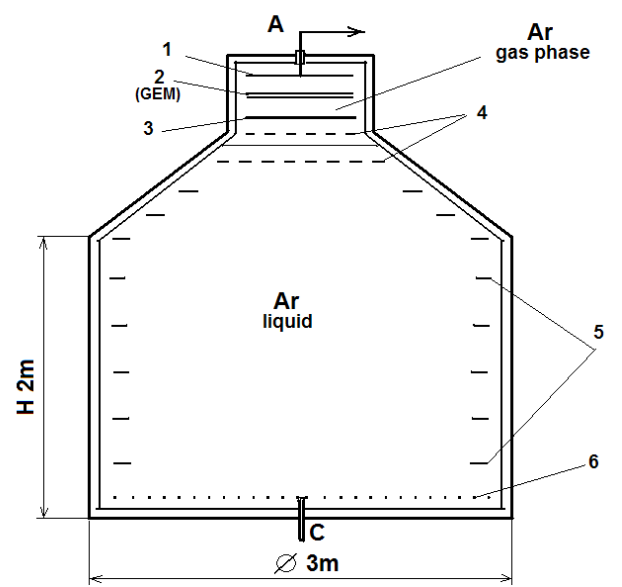

Figure 2. Double-phase Ar chamber with 20tons of Ar: 1-pin - anodes, 2 GEM detectors, 3 - light screen, 4 - grids for transport of electrons from liquid Ar to gas phase, 5 - ring electrodes for electric fieldshaping, 6 cathode

The high three-dimensional spatial resolution of GEM ensures the detection of the ionization core and photoelectrons with high efficiency.

The light screen [24] is placed between the liquid Ar and the GEM detector to block the transmission of photons from the GEM to the volume of liquid Ar. On the other hand, this screen is transparent for electrons, which are passing through it from the liquid Ar to GEM with almost 100\% efficiency. To suppress the secondary scintillation from electrons moving in the gas phase of $\mathrm{Ar}$ in the region below the light screen, hydrogen under a partial pressure of about 0,1 bar must be added to Ar gas phase. The cross section of the energy transfer in the reaction $\mathrm{Ar}_{2}{ }^{*}+\mathrm{H}_{2} \rightarrow 2 \mathrm{Ar}+\mathrm{H}_{2}{ }^{*}$ is equal to

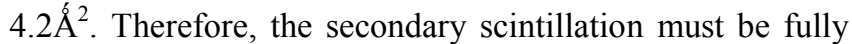
suppressed [25]. The GEMs and pin-anodes operate very stably in a mixture $\mathrm{Ar}+10 \% \mathrm{H}_{2}[26]$.

The signal from the chamber is detected by two parallel amplifiers. The detection of the total charge of the ionization electrons + photoelectrons $\mathrm{Q}_{\text {tot }}$ is achieved by a charge sensitive amplifier and the charge of the ionization electrons $Q_{\text {ion }}$ is obtained after differentiation of the signal from the chamber. This makes it possible to measure the number of photoelectrons, which is equal to $\mathrm{Q}_{\text {tot }}-\mathrm{Q}_{\text {ion }}$.

The events, which take place near the cathode and the surface of liquid Ar, can be picked out by analysis of the shape of photoelectron clouds. In addition, these events will be removed owing to the high coefficient of the background suppression.

To reduce the background produced by the cathode, it must be wound with a carbon wire of $\varnothing 1 \mathrm{~mm}$ at $50 \mathrm{~mm}$ pitch.

The ring electrodes for forming the electric field must be produced from mylar covered with copper layer of about $5 \mu \mathrm{m}$ thickness.

\section{Results}

The addition of about 100ppm Xe to liquid Ar allows the suppression of the triplet component of scintillation signals almost entirely [7]. The change of the singlet component for this addition is very little. The relationships (3) in this case are given by:

$$
\mathrm{S}_{2} / \mathrm{S}_{1}=645\left(\mathrm{e}^{-}\right), 5.31(\alpha) \text { and } 13.3(\mathrm{nr}) \text {. }
$$

The relationship $\left(\mathrm{S}_{2} / \mathrm{S}_{1}\right)_{\mathrm{e}} /\left(\mathrm{S}_{2} / \mathrm{S}_{1}\right)_{\mathrm{nr}}=48.5$ makes it possible to suppress the electron background completely [27]. This relationship doesn't depend on Ar mass.

The TMG and Xe additions do not influence each other.

The neutron background must be essentially suppressed due to multiple elastic and inelastic scattering of neutrons onAratoms in the course of their slowing [2]. The high 3D spatial resolution of the chamber restores the picture of neutron scattering and allows the suppression of this background too.

\section{Discussion}

Since the decay rate of $\mathrm{Ar}^{39}$ in 20 tons of natural argon (Fig.2) is about $2 \times 10^{4} \mathrm{~s}^{-1}$, for a $2 \mathrm{~ms}$ total collection time of electrons from this volume of the detector, only about 40 background events can take place, which gives 1 event per $500 \mathrm{~kg}$ of Ar. Therefore, the probability of the overlap of two such events is small and the $\mathrm{Ar}^{39}$ background can be completely suppressed. In a similar way the $\mathrm{Ar}^{39}$ background can be suppressed for even larger detection chambers, with a volume of $10^{4}$ tons for example. The proposed method for background suppression does not depend on Ar mass.

\section{Conclusion}


The proposed method of photosensitive TMG addition to liquid $\mathrm{Ar}$ provides nearly $100 \%$ geometric detection efficiency of the scintillation emission produced by the detected events. The addition to liquid Ar of about $100 \mathrm{ppm}$ of Xe supresses the triplet component of the scintillation emission and in presence of the TMG photosensitive addition essentially increases the coefficient of suppression of the electron background (especially of $\mathrm{Ar}^{39}$ ). The efficiency of the proposed method depends on the presence of the electronegative impurities in the Ar. Therefore, for the proposed detectors of the large mass, the deep purification of the $\mathrm{Ar}$ from the electronegative impurities is necessary. The absorption of electrons at the level of less than $50 \%$ by the impurities during the collection of the electronsdoes not change the ratio of the ionisation signal to the scintillation one $(\mathrm{S} 2 / \mathrm{S} 1)$. Therefore, it does not compromise the coefficient of the background suppression.

Finally, the proposed detection methodprovides very high coefficient of the background suppression in the liquid $\mathrm{Ar}$ detectors, the total mass of which can be up to $10 \mathrm{kt}$.

\section{REFERENCES}

[1] S.Suzuki, T.Doke, A.Hitachi et al., "Photo ionization in liquid Ar doped with trimethylamine or triethylamine", NIM A245 (1986) 366.

[2] B.M.Ovchinnikov, V.V.Parusov,"The suppression of background in experiment for WIMP search with double phase $\operatorname{Ar}(\mathrm{Xe})$ chamber", Preprint INR of RAS -0966/1997;"A method for background reduction in an experiment for WIMP search with a Xe (Ar) - liquid ionization chamber", J. Astroparticle Physics 10 (1999) 129.

[3] S.Kubota, A.Nakamoto, T.Takahashi et al., "Evidence of the existence of exciton states in liquid Ar and exciton-enhanced ionization from Xe doping", Phys. Rev. B13, No 4 (1976) 1649.

[4] D.F.Anderson, "Photosensitive dopants for liquid Ar", NIM A242 (1986) 254.

[5] D.F.Anderson, "New photosensitive dopants for liquid Ar", NIM A245 (1986) 361.

[6] S.Suzuki, T.Doke, A.Hitachi et al., "Photo ionization in liquid Xe doped with TMA or TEA", NIM A245 (1986) 78.

[7] S.Kubota, M.Hishida, M.Suzuki, J.Ruan, "Liquid and solid $\mathrm{Ar}, \mathrm{Kr}$ and Xe scintillators", NIM 196 (1982) 101; S.Kubota, H.Hishida, S.Hemi et al.,"The suppression of the slow component in Xe doped liquid Ar scintillation," NIM A327 (1993)71.

[8] WARP collaboration, "First results from a Dark matter search with liquid $\mathrm{Ar}$ at $87 \mathrm{~K}$ in the GranSasso Underground Laboratory".

[9] A.Marchionni, C.Amser, A.Badertscher et al., "Ar DM: A ton-scale liquid Ar detector for direct dark matter search", arXiv:1012.5967.

[10] B.M.Ovchinnikov, V.V.Parusov, Yu.B.Ovchinnikov, "A multi-channel wire gas electron multiplier", arXiv:1003.1240; PTE No5 (2010) 37; Instr. and Exper. Techn.,53, No 5 (2010) 653.

[11] B.M.Ovchinnikov, V.V.Parusov, Yu.B.Ovchinnikov, "A multi-channel wire gas electron multipliers with gaps between the electrodes 1 and $3 \mathrm{~mm} "$, arXiv:1005.1556; PTE No 6 (2010) 68; Instr. and Exper. Techn., 53, No 6 (2010) 836

[12] B.M.Ovchinnikov, V.V.Parusov, Yu.B.Ovchinnikov, "A multi-channel gas electron multipliers with metallic electrodes", arXiv:1006.2986; PTE No 6 (2010) 3.

[13] B.M.Ovchinnikov, V.V.Parusov, Yu.B.Ovchinnikov, "The gas electron multipliers with high reliability and stability", arXiv:1012.4716; "The methods for events detection in double-phase Ar chambers", Preprint INR of RAS No1326/2012, Moscow.

[14] P.Cennini, J.P.Revol, C,Rubbia et al.,'Improving the performance of the liquid $\mathrm{Ar}$ TPC by doping with tetra-methyl-germanium", NIM A355 (1995) 660

[15] A.S.Barabash, O.V.Kazachenko, A.A.Golubev, A.N.Zelensky, B.M.Ovchinnikov, "The system for deep Ar purification and device for electronegative admixtures measurements in noble gases and hydrocarbons", PTE, No 6 (1978) 189.

[16] A.S.Barabash, O.V.Kazachenko, A.A.Golubev, B.M.Ovchinnikov, "Catalytic and adsorbing purification of $\mathrm{NG}, \mathrm{H}_{2}, \mathrm{CH}_{4}$ from $\mathrm{O}_{2}$ ", J. "Chemical industry", 1984, No 6, p.373.

[17] A.S.Barabash, B.M.Ovchinnikov, "The purification of Ar for liquid ionization chambers with zeolites ", Preprint INR of RAS, П-0061, Moscow, 1977.

[18] A.S.Barabash, A.A.Golubev, O.V.Kazachenko, B.M.Ovchinnikov, "Liquid pulsed ionization chamber, filled with $\mathrm{Xe}, \mathrm{Ar}$ and $\mathrm{CH}_{4}$ ", Preprint INR of RAS, 1984, П-034, Moscow; NIM A236 (1985) 69.

[19] V. Vuillemin, P.Cennini, C.W.Fabjan et al., "Electron drift velocity and characteristics of ionization of alpha and beta particles in liquid argon doped with ethylene for LNC calorimetry", Preprint CERN-PPE/91-171, 1 October 1991.

[20] MiniClean Collaboration Los Alamos, "The MiniClean Dark Matter Experiment", Proceedings of the DPF-2011Conference, Providence, RI, August 8-13, 2011.

[21] Laura Baudis, "Darvin: dark matter WIMP search with noble liquids", arXiv: 1012.4764V1 [astro-ph. IM] 21 Dec. 2010.

[22] K. Arisaka, C.W. Lam, P.F. Smith at al., "Studies of a three-stage dark matter and neutrino observatory based on multi-ton combinations of liquid Xe and liquid Ar detectors", arXiv: 1107.1295V1 [astro-ph. Im] Jul. 2011.

[23] B.M. Ovchinnikov, Yu. B. Ovchinnikov, V.V. Parusov, "Proposal on large-scale liquid Ar detector for direct Dark Matter searches", Preprint INR 1307/2011, November 2011; arXiv: 1102.3588, 2012.

[24] B.M.Ovchinnikov, V.V.Parusov, T.A.Murashova, V.A.Popov. "A lightproof screen for time-projection chambers with large multiplication coefficients and photo cathodes", Instrum.Exp. Tech. 42 (1999) 386. 
[25] T. Oka, M. Kogoma, M. Imamura et al., "Energy transfer of Ar exited diatomic molecules", J. Chem. Phys., vol.70, No7 (1979) 3384.

[26] B.M.Ovchinnikov, V.V.Parusov, "The methods for events detection in two-phase Ar chambers", Preprint INR of RAS No1326/2012, Moscow.
[27] P.Picchi, F.Resnati, T.T.dF, "Liquid Ar doping for dark matter searches", http://virgilio.mib.infn.it/ $\sim$ ttf/dokuwiki/doku.php?id=dark_matter 